\title{
Conhecimentos, percepções, comportamentos e representações de saúde e doença bucal dos adolescentes de escolas públicas de dois bairros de Porto Alegre
}

\author{
Knowledge, perceptions, behaviors and \\ representations of oral health of teenagers of public \\ schools of two neighborhoods of Porto Alegre
}

Eliane Maria Teixeira Leite Flores 1

Tania Maria Drehmer 1

${ }^{1}$ Departamento de Odontologia, Saúde Bucal Coletiva da Faculdade de Odontologia/UFRGS. Rua Ramiro Barcelos $\mathrm{s} / \mathrm{n}$ 90352-001, Porto Alegre RS. elianetl@terra.com.br
Abstract The objective of this research was to assess the knowledge, perceptions, behavior and representations related to oral health of teenager students of public schools in two neighborhoods of Porto Alegre to verify the possibility of the participation of these youths as multipliers in the health assistance program. Two research instruments were used: a questionnaire and focal groups. The teenagers who participated in this research were volunteers and constituted a selected and intentional sample. The results showed that to the teenagers the tooth pain represents the illness but decay is not seen as such because it is very common as well as gingivitis, which is unevenly recognized. The personal negligence is the main cause of decay and gingivitis and the motivation to perform hygiene habits is connected to socialization. They are aware of the importance of dental floss but do not use it regularly, the dentist was the most responsible person in teaching them how to use dental floss. They showed willingness to pass on the knowledge they learned from dentists.

Key words Knowledge, Perception, Behavior, Oral health of teenagers
Resumo O objetivo desta pesquisa foi avaliar os conhecimentos, as percepções, os comportamentos e as representações relacionados à saúde bucal de adolescentes de escolas públicas de dois bairros de Porto Alegre, como também averiguar a possibilidade de participação destes como multiplicadores de saúde. Dois instrumentos de pesquisa foram utilizados: um questionário e a técnica dos grupos focais. Cinqüenta e três adolescentes constituíram uma amostra intencional. Para os adolescentes a doença cárie é representada pela dor de dente, e eles não consideram a cárie como doença, porque é comum, assim como a gengivite, que é percebida como um desequilíbrio. A negligência pessoal é considerada a principal causa da cárie e da gengivite, e a motivação para realizar a higiene bucal está vinculada à sociabilização. O dentista foi indicado como responsável pelo ensinamento do uso do fio dental e pelo reforço e aperfeiçoamento da técnica de escovação. Os adolescentes demonstram disposição em transferir os conhecimentos sobre saúde que receberam para seus colegas mais jovens.

Palavras-chave Conhecimento, Percepção, Comportamento, Saúde bucal de adolescentes 


\section{Introdução e objetivos}

Uma das contribuições da promoção de saúde é a educação que visa ampliar o entendimento sobre saúde, concorrendo para o processo em que a comunidade aumente a sua habilidade de resolver seus próprios problemas com competência e intensifique sua própria participação. Essa atividade pode ser desenvolvida em espaços diversos, como escolas, por exemplo, permitindo a expansão e o fortalecimento da saúde através de um trabalho coletivo e participativo com toda a comunidade escolar (Sheiham e Moysés, 2000).

O Departamento de Odontologia Preventiva e Social da Faculdade de Odontologia da Universidade Federal do Rio Grande do Sul realiza, desde 1983, um programa educativo-preventivo em escolas localizadas nos bairros Lomba do Pinheiro e Agronomia, e atendimento clínicoodontológico no Módulo de Serviço Comunitário (MSC) do Centro de Pesquisa em Odontologia Social (CPOS-UFRGS). Nesse programa, os alunos de 5a série em diante, depois de participarem com entusiasmo das atividades propostas pelos acadêmicos, passam a demonstrar indiferença às exposições dos futuros dentistas sobre o tema saúde bucal e ao tratamento preventivo e curativo que lhes é facilitado. Entender as causas desse comportamento permitiria adequar a ação do programa às necessidades desses jovens. Com o intuito de buscar a solução para o problema, foi identificado na literatura como recurso estratégico a incorporação dos escolares como multiplicadores de conhecimentos sobre saúde e doença bucal. Mas para isso era necessário investigar o conhecimento absorvido, as percepções, conceitos, opiniões, expectativas e representações sociais do universo cultural das pessoas a serem atingidas, o que permitiria uma aproximação com a comunidade focalizada (Westphal, Bógus e Faria, 1997).

O objetivo do estudo foi, portanto, inquirir e avaliar adolescentes quanto aos conhecimentos, percepções, hábitos e comportamentos, $\mathrm{e}$ às representações da saúde e doença bucal para viabilizar o recurso estratégico. A importância do papel dos dentistas (acadêmicos de odontologia) para sua saúde e a disponibilidade de participar do programa como multiplicadores de saberes em saúde, também, foram avaliadas. Neste artigo serão apresentados alguns dos resultados, buscando a confrontação das respostas obtidas em questionário e em entrevistas (grupos focais).

\section{Revisão de literatura}

Segundo Aberastury e Knobel (1992), entre as características psicológicas dos adolescentes estão a busca de identidade, os desequilíbrios e instabilidades extremas, a alternância de períodos de altivez, introversão, audácia, timidez, descoordenação, urgência, desinteresse e apatia, os conflitos afetivos e as crises religiosas, apresentando ainda, condutas sexuais dirigidas para o heteroerotismo e para homossexualidade.

Segundo Rassial (1995), quando uma criança entra no processo de adolescência, questiona de forma radical sua identidade, a dos seus pais, assim como a sociedade em que vive. Segundo Bee (1997), por serem surpreendentes as mudanças físicas e emocionais que são parte dessa transição, o período da adolescência adquiriu uma reputação tempestuosa e estressante, o que não é exagerado, tal a importância do processo.

Blos (1996), resumidamente, diz que $a$ puberdade é um ato da natureza, e a adolescência, um ato do homem, o que acentua o fato de que nem o término do crescimento físico, nem o alcance do funcionamento sexual, nem o papel social da auto-suficiência econômica são, por si só, referências confiáveis para o término do processo adolescente. A palavra adolescência é usada para se referir ao período entre a infância e a vida adulta, estendendo-se dos 14 aos 25 anos, no homem, e dos 12 aos 21, na mulher.

Outeiral, em 1994, e Aberastury e Knobel, em 1992, afirmam que é muito difícil assinalar o limite entre o normal e o patológico na adolescência e consideram que, na realidade, toda a comoção desse período da vida deve ser considerada normal, assinalando também que seria anormal a presença de um equilíbrio estável durante o processo adolescente.

$\mathrm{O}$ adolescente encontra, na micro-sociedade da escola, um sistema de forças que atua sobre ele, no qual, entre outras coisas, ele reedita seu ciúme fraterno, compete, divide, rivaliza, oprime e é oprimido, isto é, reproduz o sistema social (Outeiral, 1994). A condição contemporânea da sociedade é um fator contribuinte decisivo no comportamento do adolescente (Blos, 1996).

O Ministério da Saúde (Brasil, 1997) considera que a escola representa um ambiente educacional e social propício para se trabalhar conhecimentos e mudanças de comportamento. A Organização Mundial de Saúde (OMS) preconiza ainda a formação de adolescentes mul- 
tiplicadores, visando promover a qualidade de vida e a saúde integral do adolescente (Brasil, 1997).

As percepções, os conhecimentos, o comportamento de adolescentes em relação à saúde bucal foram estudados por diversos autores, em diversos países do mundo como: Linn (1976); Blinkhorn (1993, 1998); MacGregor, Balding e Regis (1998); Gilbert (1994); MacGregor, Balding e Regis (1997); Watt (1997a e b); Thomson, Locker e Poulton (2000). No Brasil, pesquisadores como Silva, Paixão e Pordeus (1997); Tamietti, Castilho e Paixão (1998) e Freire (1999) desenvolveram trabalhos com adolescentes. Observa-se, pela literatura, que esses fatores são influenciados pela sociedade a que pertencem.

\section{Material e métodos}

Como não existe uma padronização de estudos não clínicos em odontologia (Buck e Newton, 2001), optou-se por utilizar duas técnicas para coleta das informações: a técnica dos questionários, que permite coletar informações de forma simultânea em um universo maior de pessoas, e a técnica dos grupos focais.

O sinergismo dos efeitos da combinação das diferentes técnicas para responder e analisar questões é reconhecido pelos pesquisadores envolvidos na avaliação de intervenções em promoção de saúde. Conforme Nutbeam (1998), a triangulação, que significa usar mais de uma abordagem para responder às mesmas questões, melhora a confiança e a consistência dos resultados

O questionário elaborado por Brew (1999) foi adaptado para este estudo e contém 57 questões com o objetivo de avaliar a situação socioeconômica das famílias dos adolescentes, o conhecimento e os hábitos desses adolescentes a respeito de saúde bucal e quanto à possibilidade de se tornarem agentes multiplicadores de conhecimentos em saúde. O grupo focal, segundo Stewart e Shamdasani, em 1990, de outra forma, permite conhecer com maior profundidade as crenças e valores, os comportamentos, como também a identificação das representações de saúde/doença.

Das seis escolas estaduais em que se desenvolve o programa docente-assistencial foram escolhidas as escolas estaduais Desidério Torquato Finamor, Onofre Pires e Rafaela Remião, situadas nos bairros Agronomia e Lomba do
Pinheiro. A escolha das escolas foi intencional bem como a dos adolescentes de 7ạ série. Em 2000, eram 170 adolescentes. Desses, 113 foram autorizados pelos pais a responderam ao questionário e, finalmente, 53 alunos se dispuseram voluntariamente a participar dos grupos focais.

Os dados dos questionários dos 53 alunos foram apresentados em tabelas de freqüência absolutas e percentuais. Os diálogos dos 7 grupos focais realizados foram interpretados de forma a compreender os significados das percepções e dos comportamentos usuais dos atores sociais através do método denominado Hermenêutica-Dialética, descrito por Minayo (2000).

As características dos adolescentes, bem como as de suas famílias, eram as que se seguem: os adolescentes tinham entre 12 e 18 anos; $54,7 \%$ eram do sexo masculino; $26,4 \%$ já estavam inseridos no mercado de trabalho informal e formal; a renda média familiar era de $\mathrm{R} \$ 605,70$, variando entre $\mathrm{R} \$ 60,00$ e $\mathrm{R} \$ 1.850,00$; $32,1 \%$ dos pais e $23,2 \%$ das mães biológicas não estavam presentes no lar; $3,7 \%$ dos pais e $1,9 \%$ das mães ou responsáveis eram analfabetos, enquanto $9,4 \%$ dos pais e $1,9 \%$ das mães ou responsáveis chegaram ao $3^{\circ}$ grau, tendo a maior parte o primeiro grau completo; $92,5 \%$ tinham água tratada em casa, sendo que 71,1\% moravam em casas de alvenaria.

\section{Resultados e discussão}

Nos grupos focais os adolescentes expuseram o que pensam e sentem sobre a sua saúde bucal. De acordo com a literatura (Stewart e Shamdasani, 1990), as discussões devem começar com um tema abrangente. Por essa razão iniciavamse os encontros dos grupos com a pergunta - $\mathrm{O}$ que é doença para vocês? Entre as respostas registradas encontramos: - Muito ruim! - Doença eu acho que é uma coisa muito ruim de ter, porque afeta o organismo. Têm pessoas que ficam depois abaladas por causa da doença. - É horrível! - Eu tenho asma, sora! Não posso correr muito, subir lomba - Eu já tive uma gripe bem forte. Quase morri, sora! Como experiências pessoais, também mencionaram a catapora, o sarampo, caxumba, coqueluche, aroeira, bronquite, pontada, bronquite crônica e dor de dente.

Observa-se que os jovens consideram doenças as enfermidades que modificaram sua rotina e que os impediram de ir à escola ou de realizar atividades corriqueiras como correr, 
subir lomba e as que os colocaram na cama. A dor de dente foi identificada como doença, quando, na verdade, se trata de um sintoma, e o termo foi utilizado pelos adolescentes como se fosse a própria doença. Ferreira (1998) também observou que qualquer alteração na qualidade de vida, quando o indivíduo não consegue trabalhar, comer, dormir ou realizar atividade que está habitualmente acostumado, implica estar doente. Mas Helman (1994) afirma que os fatores culturais determinam quais os sinais ou sintomas que são percebidos como anormais. Boltanski (1984), também, cita que a percepção da dor varia de acordo com o grupo social. A percepção da dor como doença grave aumenta nas classes superiores em relação às baixas.

Segundo Ferreira (1995), a sensação de dor, os comportamentos que a envolvem, quer verbais ou não, até as atitudes que visam remover ou não a sua fonte dizem respeito às expectativas do sujeito, às suas experiências passadas e, principalmente, a toda sua bagagem cultural. Ferreira (1998) acrescenta que a observação mostra, no entanto, que não é a dor que varia conforme a classe, mas sim a continuidade das atividades e a busca de alívio do sintoma.

A dor costuma ser indicada como uma sensação "desprazerosa”, e sua condição de sintoma torna implícita a possibilidade de uma patologia. $\mathrm{O}$ fato de as palavras dor e doença possuírem uma raiz etimológica comum (no latim, dolor e dolentia) é, por si só, bastante expressivo da íntima relação que existe entre a experiência de dor e o reconhecimento de um estado mórbido (Ferreira, 1998).

Os registros sobre o reconhecimento da cárie como doença obtidos pelos questionários desses 53 alunos podem ser observados na tabela 1 . Observa-se que $64,15 \%$ responderam que a consideram como doença. Dos 36 (67,92\%) que experienciaram cárie, 26 reconheceram cárie como doença, e apenas 4 não a reconheceram como tal. Dezessete adolescentes não assinalaram a cárie como experiência (o que representa um terço do total de participantes), entre os quais estão oito que reconheceram a cárie como doença. A probabilidade associada (P) ao teste qui-quadrado não mostrou associação entre as duas variáveis, evidenciando que a presença de cárie não indica necessariamente que ela seja considerada doença pelos jovens pesquisados.

Seria relevante o fato de que aqueles que tiveram cárie a reconhecessem em maior número, o que se mostraria coerente com o sofrimento determinado pelas conseqüências que essa doença provocou, como foi relatado nos grupos focais. Nesses, no entanto, a pergunta Cárie é doença? foi respondida como segue: É um problema! - É igual, parecido! - Não é doença, mas é ruim! - É ruim! - Doença não! Ah, não que não seja importante, mas é comum! Helman (1994) observou que sintomas e sinais muito comuns, provavelmente, serão considerados normais, embora não necessariamente bons e, por conseguinte, aceitos de uma forma fatalista.

Ao serem questionados sobre outros problemas bucais, com a pergunta: Além da cárie, o que vocês notaram na boca que também incomoda?, as respostas foram: - A minha gengiva sangra! - Gengiva? A minha sangra... quase sempre! - A minha não! - Eu acho que eu tenho inflamação, parece que lateja assim, de vez em quando, daí lateja, faz assim (enfatizando com a mão) e pára; daí começa de novo.

As considerações sobre doença da gengiva foram colocadas da seguinte forma: - Gengivite é doença? - Não, é placa! Placa não é doença! Não é doença, mas deve ser alguma coisa que tá

Tabela 1

Distribuição dos adolescentes quanto à freqüência da experiência de cárie e o reconhecimento da cárie como doença - Porto Alegre, 2000.

\begin{tabular}{lrrrrrrr}
\hline $\begin{array}{l}\text { Experiência de cárie/ } \\
\text { Cárie é doença? }\end{array}$ & No & Sim & $\%$ & № & Não & № & Total \\
\hline Sim & 26 & 72,22 & 8 & 47,06 & 34 & 64,15 \\
Não & 4 & 11,11 & 3 & 17,65 & 7 & 13,21 \\
Não sei & 6 & 16,67 & 6 & 35,29 & 12 & 22,64 \\
Total & 36 & 67,92 & 17 & 32,08 & 53 & 100,00 \\
\hline
\end{tabular}

Teste Qui-quadrado: $\mathrm{P}=0,1937$ 
acontecendo... sei lá! Eu acho que é normal! Acho normal também! Não acontece com um nem com outro, acontece com todos! Segundo Brunswick e Nikias (1975), Gilbert (1994), o sangramento gengival não era percebido, pelas populações por eles pesquisadas, como problema que mereça tratamento.

Sobre o problema sangramento gengival, o depoimento de um aluno foi: - Às vezes a gente tá doente, e a gengiva também tem essa coisa, às vezes ela sangra, às vezes não sangra, mas isso não é uma coisa muito complicada. - Acho que não tem muito mistério! Tá e não tá, deu...!

Como representação da doença as falas do jovem dão a idéia de equilíbrio e de desequilíbrio. Na interpretação antropológica de Laplantine (1991), essa compreensão do normal e do patológico está caracterizada pela particularidade única de um equilíbrio e também pela predisposição a um certo desequilíbrio.

A responsabilidade pessoal pela causa da cárie parece ser a razão com mais significado para que esta se estabeleça, como pode ser observado na tabela 2. Nos grupos focais, as respostas sobre quais seriam as causas da cárie foram: Porque eu não cuidei! - Como muito doce, chiclé! - Eu também! - A cárie vem do doce. Daí não escova os dentes direito, não limpa a boca direito, $e$ dá cárie! - Comê doce demais e não limpá! Quando a gente vem pro colégio, come muito doce e fica muito tempo sem escovar os dentes! Essas percepções, provavelmente, são conseqüência da influência dos acadêmicos de odontologia que propagam o que lhes é ensinado, ou seja, que é a negligência com o auto-cuidado e a ingestão exagerada de açúcar as principais razões para o aparecimento da doença.

Watt (1997b), ao analisar os modelos empregados para promover a saúde bucal, é de opinião que, ao culpar o doente pelas suas enfermidades devido ao seu comportamento, encobre-se o fracasso das políticas de saúde em lidar com os fatores sociais, econômicos e ambientais inerentes ao processo saúde/doença.

Para os estudantes das sétimas séries dessas escolas, os cuidados com a alimentação têm uma importância de menor significado, ficando em quinto lugar na escolha das respostas de como se deve cuidar dos dentes (Tabela 3). Esse menor valor, provavelmente, está associado à dificuldade em mudar hábitos alimentares mais do que propriamente ao desconhecimento da importância dos alimentos para a qualidade de vida, e por conseqüência, para as condições bucais, como também, encontrou Watt (1997a) na Inglaterra. Reisine e Litt (1993) e Blinkhorn $(1993,1998)$ admitem que o conhecimento isoladamente não é suficiente para melhorar as condições de saúde bucal

Nas conversas com os adolescentes sobre os seus hábitos de higiene, aparece como a principal motivação para realizá-los a questão do mau hálito - Pra evitar o bafo, pra não derrubar ninguém! ou pela vergonha que estão associados ao contato com os outros colegas, amigos(as) ou namorados(as).

As relações sexuais, a associação da boca com o comer alimentos e a expressão comer para designar a relação sexual foi particularmente discutida em três grupos de duas diferentes escolas, tendo os estudantes manifestado maior interesse em conversar sobre sexo do que saúde bucal. Consideram de grande importância discutir a sexualidade pelo que ela representa para a vida de todos. Segundo Ceccon e Eisenstein (2000), os momentos felizes são tão importantes para crescer como a quantidade e a qualidade de alimentos. Os principais alimen-

Tabela 2

Distribuição de adolescentes quanto às respostas assinaladas sobre as causas da cárie dental - Porto Alegre, 2000.

\begin{tabular}{lcc}
\hline Causa & No & \% \\
\hline Não escovar ou escovação inadequada & 45 & 84,9 \\
Germes, bactérias & 42 & 79,2 \\
Alimentos entre os dentes & 36 & 67,9 \\
Comidas, doces e lanches & 31 & 58,5 \\
Antibióticos & 7 & 13,2 \\
Comer alimentos muito duros & 3 & 5,66 \\
\hline
\end{tabular}


tos de qualquer criança ou adolescente são a comunicação, os jogos e o amor, que se transformam nos vínculos de afeto mais significativos com o mundo a sua volta.

As falas sobre as razões para os cuidados bucais reproduzem os achados de Linn (1976), Regis, MacGregor e Balding (1991), Silva, Paixão e Pordeus (1997) e MacGregor, Balding e Regis (1997), no que se refere ao querer evitar o mau hálito e manter uma boa aparência para facilitar a sociabilização.

Os dados de MacGregor, Balding e Regis (1998) informam que a freqüência da escovação e do uso do fio dental está associada à freqüência das visitas ao dentista, pois este motiva e reforça os ensinamentos de como e por que usar o fio dental. Neste estudo observa-se que $85 \%$ dos adolescentes entrevistados registraram visita ao dentista em 1999/2000 (Flores, 2001). Todos (100\%) assinalaram a escovação como meio de cuidar dos dentes (Tabela 3) e $90,55 \%$ deles a realizam de 3 a 4 vezes ao dia, mas apenas $66,03 \%$ confirmaram usar o fio dental (Tabela 4).
Nos grupos focais as respostas sobre a questão do uso do fio dental foram: -Eu uso. -De vez em quando! - Eu não uso! - É lá uma vez que outra! - Preguiça! - Eu esqueço! - Tranca nos dentes! - É chato de usar! Acho xarope, eu acho! - Eu consigo colocar o fio dental somente nos dentes da frente, nos de trás eu não consigo! A resistência ao uso do fio dental é observada entre os jovens. Apontam a dificuldade do seu uso pela habilidade requerida, pois necessita de treino, e a preguiça em adotá-lo como recurso de rotina. O uso do fio fica para situações especiais, como festas de fim de semana. MacGregor, Balding e Regis (1998) demonstraram que o uso do fio está positivamente relacionado a outros comportamentos de saúde e disponibilidade de relacionamento social. Também registraram que um grande número de adolescentes usa o fio algumas vezes ou pelo menos uma vez por semana, mas não todos os dias.

Os dentistas neste estudo foram identificados como os responsáveis pelo ensinamento da escovação por $26,42 \%$ dos jovens. Já em relação ao fio dental o percentual passou a $56,60 \%$

Tabela 3

Distribuição dos adolescentes quanto às respostas de como cuidar dos dentes - Porto Alegre, 2000.

\begin{tabular}{lcc}
\hline Como cuidar dos dentes? & № & \% \\
\hline Escovando os dentes & 53 & 100,00 \\
Indo ao dentista & 51 & 96,23 \\
Usando pasta de dente com flúor & 51 & 96,23 \\
Usando fio dental & 49 & 92,45 \\
Evitando comer doces & 35 & 66,04 \\
Evitando comer gorduras & 5 & 9,43 \\
Comendo várias vezes ao dia & 2 & 3,77 \\
\hline
\end{tabular}

Tabela 4

Distribuição dos adolescentes quanto à freqüência de escovação e do uso do fio dental - Porto Alegre, 2000.

\begin{tabular}{lcccc}
\hline Freqüência ao dia & Escova & \% & Fio dental & \% \\
\hline 1 & 2 & 3,78 & 21 & 39,62 \\
2 & 3 & 5,67 & 8 & 15,09 \\
3 & 28 & 52,75 & 2 & 3,77 \\
4 & 20 & 37,80 & 4 & 7,55 \\
Não usa & - & - & 17 & 32,08 \\
Não respondeu & - & - & 1 & 1,89 \\
Total & 53 & 100,00 & 53 & 100,00 \\
\hline
\end{tabular}


(Tabela 5). Pode ser deduzido dessas questões que, enquanto o hábito da escovação é usual nas famílias desses adolescentes, o uso do fio dental é menos freqüente. Nos grupos focais, os adolescentes relataram que a importância dos dentistas estava no reforço e no aperfeiçoamento da técnica da escovação que haviam aprendido com as mães. Uma jovem descreveu uma consulta da seguinte maneira: - A minha dentista (acadêmica) falou, ela conversou bastante comigo. Ela marcou aqui na escola, né? Aí ela pediu pra mim ir lá no Módulo (MSCUFRGS). Aí na primeira consulta que eu fui ela conversou bastante sobre isso.(...) Ela ensinou bastante coisas, até como escovar os dentes, que a gente acha até que tá escovando bem, só que tem uma certa maneira de escovar os dentes. - E tu achas que tu melhoraste a tua forma de escovar depois disso ou não? - Eu acho que sim, porque antes eu achava que sabia, só que eu não sabia direito como era.

Outra adolescente declarou as suas experiências com os acadêmicos da UFRGS da seguinte maneira: - Quando eu era menor me saiu uma cárie, daí começou a doer, daí chorei a noite toda... aí me atenderam no Módulo. Fizeram uma obturação, botaram a massinha. Daí depois me encaminharam mais uma vez aqui pelo colégio, daí eu arrumei todos os meus dentes, porque eu tinha dois aqui de trás acavalados, ai arrumaram, arrumaram todos os meus dentes, me ensinaram a escovar, passar fio dental, passar flúor. Daí eu fui lá, eu sempre fui lá, nunca fui em outro dentista, sempre direto ali. - O meu dentista era muito querido. Ele me tratou um ano inteirinho, só ele que cuidava dos meus dentes, lá no Módulo.

As experiências sobre o contato com os acadêmicos foram narradas com uma expressão de satisfação, de gratidão e reconhecimento pelas atitudes de acolhimento e atenção por parte deles. O assunto sobre a indiferença dos adolescentes em relação ao trabalho desenvolvido pelos acadêmicos no programa preventivoeducativo-curativo trouxe, também, esta declaração: - O problema não são os dentistas, o problema é a escola... sei lá, não tem nada pra fazer só estudar, estudar, estudar. O tédio manifestouse como um problema da escola onde sempre se faz tudo igual.

O tédio, de acordo com Angerami-Calmon (1999), determina uma certa caracterização do jovem atual, pois, além de uma certa maneira específica de comportamento, ainda lhe confere um inconformismo pela necessidade de mudança-características que dizem respeito a sua maneira de discorrer e reivindicar direitos sobre a sua condição de jovem. É também o tédio o que confere insatisfação em realizações concretizadas diante do muito que ainda pode ser feito.

Os problemas oriundos da resistência às orientações sobre prevenção e tratamento dos problemas bucais dadas pelos acadêmicos de odontologia, nesse programa, decorrem, provavelmente, do fato de se tratar de adolescentes que apresentam características naturais de contraposição ao estabelecido (Moraes e Ongaro 1998) e pelo fato de estarem ainda à procura da sua identidade, conforme a literatura pesquisada (Aberastury e Knobel, 1992; Blos, 1996, Outeiral, 1994; Bee, 1997).

Jandrey (1999) identificou os motivos pelos quais ocorre absenteísmo de escolares no atendimento clínico-odontológico realizado no Módulo (MSC). Entre outros, destacaram-se o medo e a ansiedade ao atendimento odontológico, a representação de que não havia significado em cuidar dos dentes e o sentimento de exclusão social.

A figura 1 mostra que $87 \%$ dos adolescentes não reconhecem ter medo de ir ao dentista.

Tabela 5

Distribuição dos adolescentes quanto às respostas sobre as pessoas que lhes ensinaram a escovar os dentes e a usar o fio dental - Porto Alegre, 2000.

\begin{tabular}{lcccc}
\hline Quem ensinou & Escovar & \% & Usar fio & \% \\
\hline Mãe & 34 & 64,15 & 18 & 33,96 \\
Pai & 18 & 33,96 & 12 & 22,64 \\
Dentista & 14 & 26,42 & 30 & 56,60 \\
Sozinho & 6 & 11,32 & 6 & 11,32 \\
Outros & 1 & 1,89 & - & - \\
Não usa & - & - & 10 & 18,87 \\
\hline
\end{tabular}


Thomson, Locker e Poulton (2000) relatam que o medo é mais encontrado entre aqueles que procuram atendimento para resolver um problema dentário do que por aqueles que visitam o dentista para fazer revisões, e a maior ansiedade encontra-se entre os que evitam o consultório odontológico.

O seguinte relato foi ouvido de um jovem sobre sua percepção da existência de uma cárie, ainda quando ela era menor: - Até me dava conta, mas eu não ia ao dentista, porque eu tinha muito medo. E acrescentou, esclarecendo: Uma vez eu fui no dentista tratar um dente, ai eu acho que a anestesia não funcionou, eu senti muita dor, mas tanta dor no dente, que depois daquele dia, eu acho que fiquei com trauma. Não sentia vontade de falar com dentista, com ninguém... agora tá bem melhor do que antes; (o jovem está se referindo ao contato com os dentistas na escola através do programa realizado em um ambiente diferente do consultório, que é a própria escola).

A dor impulsiona o indivíduo para o tratamento que, por sua vez, tem grande probabilidade de produzir dor ou desconforto. Os inúmeros casos de faltas, cancelamentos e atrasos que ocorrem na clínica odontológica representam exemplos típicos de fuga de tratamento, nos dizeres de Moraes e Ongaro (1998).

Essa questão suscitou o surgimento de relatos de percepções antagônicas sobre o sentir a dor e procurar alívio através de tratamento odontológico. As seguintes respostas seguiram à pergunta: - A dor de dente, sem o dentista, e a dor de dente lá dentro do consultório; qual foi a pior? - A sozinha! Tu não sabe porque tá tendo aquela dor. - Ah! Eu prefiro ir no dentista pra tirá a cárie do que ficá com ela. Outra adolescente contradisse a colega da seguinte maneira: - Eu posso ter cárie, mas não suporto dentista!

$\mathrm{Na}$ interpretação de Moraes e Ongaro (1998), a condição de incerteza do conhecimento do paciente odontológico, que tanto pode desconhecer suas condições de saúde bucal como também a natureza das intervenções necessárias, se exterioriza através do estado ansioso. As falas refletem a incapacidade individual para lidar com o conflito e a ansiedade provocada pelo tratamento odontológico, o que é confirmado pelos estudos de Milgrom e Weinstein (1993) e Eli, Uziel, Baht e Kleinhauz (1997). Estes afirmam que mesmo sendo o tratamento acompanhado por dor, não necessariamente será acompanhado por ansiedade ou fobia, pois esta é uma característica psicológica do indivíduo que pode estar ou não relacionada com experiência anterior de sofrimento por tratamento odontológico.

A disponibilidade de ensinar os conhecimentos sobre saúde bucal foi respondida afirmativamente nesse questionário por apenas 17 adolescentes; 13 não se dispuseram a executar

\section{Figura 1}

Distribuição de adolescentes quanto ao medo às visitas ao dentista - Porto Alegre, 2000

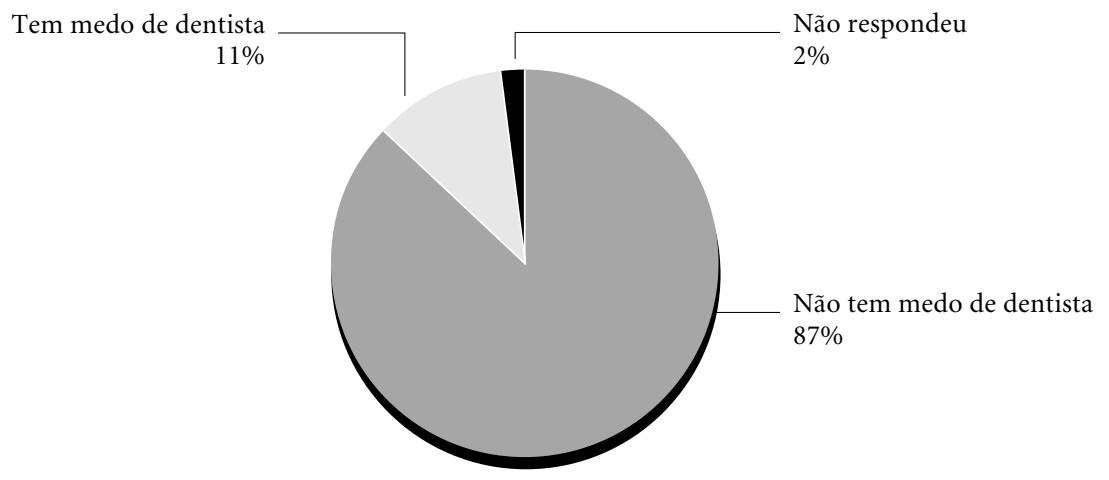


tal tarefa; e 23 não definiram um posicionamento. No entanto, durante os encontros dos grupos focais, muitos dos participantes simpatizaram com a idéia de transmitir seus conhecimentos às crianças da sua própria escola. $\mathrm{O}$ sentimento de ligação e interdependência entre as pessoas de uma comunidade, como a escola, transparece nas falas dos jovens, assim como a consciência da capacidade de transmissão de conhecimento e valores.

Foi dito nos diálogos que mobilizar as crianças era mais fácil do que ensinar aos da mesma idade, os adolescentes. As palavras esclarecedoras de uma jovem foram: - Ensinar os pequenos é muito bom e divertido. Agora, com adolescente é muito mais difícil! Não se sabe nunca como vai ser... Porque a gente não sabe como eles vão reagir. Eu, por exemplo, quando os dentistas chegaram a primeira vez, eu nem dei bola!

A compreensão, por outro lado, de que eles são tão ou mais capazes de ensinar e atingir os menores pelo reconhecimento da semelhança, por pertencerem à mesma comunidade escolar e se conhecerem mais, foi claramente argumentada por este diálogo em outra turma. - Qual a importância para vocês de ensinarem os alunos menores, vocês pensam que faria diferença entre vocês e os dentistas? - Acho que faria diferença... - Acho que a gente ia ensiná pra eles o que a gente aprendeu com eles, com os dentistas. E eles iam vê como a gente fala com os pequenos, porque eles não entendem muito bem (...) É uma coisa legal a gente passá pra eles o que a gente aprendeu. - Uma experiência nova, né? - É uma coisa que vai crescendo! - Vai, a gente ensina eles e aí outras crianças vão sentindo curiosidade. - Faz uma cadeia! - Com a gente eles vão ter mais liberdade do que com os dentistas (acadêmicos), porque eles nos conhecem e eles vão ter mais liberdade de chegar e falar. Esse último comentário foi bastante explícito em demonstrar a distância que os adolescentes percebem existir entre os acadêmicos e a população a qual pertencem.

\section{Conclusões}

Dos dados coletados neste estudo, pode-se concluir que:

- os jovens consideram doença as enfermidades que modificam sua rotina, quando impedem que realizem suas atividades habituais;

- a maioria reconhece a cárie como doença e já passaram pela experiência. No entanto, por serem consideradas problemas comuns, tanto a cárie como a gengivite são aceitas como normais e decorrentes de situações de desequilíbrio;

- a negligência pessoal é considerada pelos adolescentes causa dos problemas bucais;

- as razões mais citadas para a limpeza dos dentes são evitar o mau hálito e manter uma boa aparência. $\mathrm{O}$ mau hálito traz sentimentos de vergonha, por lhes dificultar a comunicação e, por conseqüência, a sociabilização;

- a importância do uso do fio dental é reconhecida, apesar de não o utilizarem freqüentemente e muitos registraram que não o usam;

- foram orientados tanto na família como na escola sobre os cuidados com a higiene bucal, sendo que o dentista foi indicado como responsável pelo reforço e aperfeiçoamento da técnica de escovação e ensinamento do uso do fio dental;

- o tédio da rotina escolar e as características comportamentais próprias da adolescência parecem ser a causa da indiferença dos jovens, observada pelos acadêmicos, os quais são apontados como atenciosos e compreensivos;

- uma minoria (11\%) reconheceu que tem medo de ir ao dentista, geralmente, em conseqüência de experiências desagradáveis por tratamentos dolorosos;

- a maioria dos adolescentes que participaram dos grupos focais mostrou-se disposta a transmitir às crianças das suas escolas os conhecimentos que adquiriram.

\section{Referências bibliográficas}

Aberastury A \& Knobel MA 1992. A adolescência normal. Artes Médicas, Porto Alegre.

Angerami-Calmon VA 1999. O tédio na adolescência. Papirus, Campinas.

Bee H 1997. O ciclo vital. Artes Médicas, Porto Alegre.

Blinkhorn AS 1993. Factors affecting the compliance of patients with preventive dental regimens. International Dental Journal 43(3):294-298. 
Blinkhorn AS 1998. Dental health education: what lessons have we ignored? British Dental Journal 184 (2):58-59.

Blos P 1996. Transição adolescente: questões desenvolvimentais. Artes Médicas, Porto Alegre.

Boltanski L 1984. As classes sociais e o corpo. Graal, Rio de Janeiro.

Brasil 1997. Criança, adolescente e adulto jovem. Brasília. Documento de referência para o trabalho de prevenção das DST, Aids e drogas. Ministério da Saúde. Coordenação Nacional de DST e Aids.

Brew M 1999. Conhecimentos, hábitos e atitudes de adolescentes da cidade de Torres em relação à saúde bucal. Dissertação de mestrado em odontologia, Universidade Luterana do Brasil, Faculdade de Odontologia, Canoas.

Brunswick AF \& Nikias M 1975. Dentist's ratings and adolescents perceptions of oral health. Journal Dental Research 54(4):836-843.

Buck D \& Newton JT 2001. Non-clinical outcome measures in dentistry: publishing trends 1988-98. Community Dentistry Oral Epidemiology 29(1):2-8.

Ceccon C \& Eisenstein E 2000. Saúde, vida e alegria: sugestões metodológicas. Artes Médicas, Porto Alegre.

Eli I, Uziel O, Baht R \& Kleinhauz M 1997. Antecedents of dental anxiety: learned responses versus personality traits. Community Dentistry Oral Epidemiology 25(3):233-237.

Ferreira J 1995. Semiologia do corpo. In OF Leal. Corpo e significado: ensaios de antropologia social. UFRGS, Porto Alegre.

Ferreira J 1998. O corpo sígnio. In MCS Minayo \& PC Alves (orgs.). Saúde, doença um - olhar antropológico. Fiocruz, Rio de Janeiro.

Flores E 2001. Percepções, comportamentos, conhecimentos e representações sociais da saúde e doença bucal de adolescentes. Dissertação de mestrado em saúde bucal coletiva. Universidade Federal do Rio Grande do Sul, Faculdade de Odontologia, Porto Alegre.

Freire MCM 1999. Oral health and sense of coherence: a study of Brazilian adolescents and their mothers. Tese de doutorado, University of London, Londres.

Gilbert L 1994. Social factors and self-assessed oral health in South Africa. Community Dentistry Oral Epidemiology 22(1):47-51

Helman CG 1994. Cultura, saúde e doença. (2a ed.). Artes Médicas, Porto Alegre.

Jandrey CM 1999. Absenteísmo no atendimento clínicoodontológico: o caso do módulo de saúde comunitária do CPOS. Dissertação de mestrado em saúde bucal coletiva. Universidade Federal do Rio Grande do Sul, Faculdade de Odontologia, Porto Alegre.

Laplantine F 1991. Antropologia e doença. Martins Fontes, São Paulo.

Linn EL 1976. Teenagers attitudes, knowledges and behavior related to oral health. Journal of the American Dental Association 92(5):946-951.

MacGregor IDM, Balding JW 1991. Self-steem as a predictor of toothbrushing behaviour in young adolescents. Journal Clinical Periodontology 18(5):312-316.

MacGregor IDM, Balding JW \& Regis D 1997. Motivation for dental hygiene in adolescents. International Journal Paediatric Dentistry 7:235-241.
MacGregor IDM, Balding JW \& Regis D 1998. Flossing behavior in English adolescents. Journal Clinical Periodontology 25(4):291-296.

Milgrom P \& Weinstein P 1993. Dental fears in general practice: new guidelines for assessment and treatment. International Dental Journal 43(4):288-293.

Minayo MCS 2000. Fase de análise ou tratamento do material. In $O$ desafio do conhecimento: pesquisa qualitativa em saúde. (7ạ ed.). Hucitec, São Paulo. (Saúde em Debate, 46).

Moraes ABA \& Ongaro S 1998. Contribuição da psicologia da saúde à odontologia. In C Botazzo \& SFT Freitas (orgs.). Ciências sociais e saúde bucal: questões e perspectivas. Edusc, São Paulo.

Nutbeam D 1998. Evaluating health promotion-progress, problems and solutions. Health Promotion International 13(1):27-44.

Outeiral J 1994. Adolescer, estudos sobre adolescência. Artes Médicas, Porto Alegre.

Rassial JJ 1995. Entrevista com J. J. Rassial. Revista Associação Psicanalítica de Porto Alegre 5(11):86-100.

Reisini S \& Litt M 1993. Social and psychological theories and their use for dental practice. International Dental Journal 43(4):279-287.

Silva TA, Paixão HH \& Pordeus IA 1997. Fatores do comportamento relacionado à higiene bucal em adolescentes. Arquivos em Odontologia 33(1):5-14.

Sheiham A \& Moysés SJ 2000. O papel dos profissionais de saúde bucal na promoção de saúde, pp. 23-37. In YP Buisch. Promoção de saúde bucal na clínica odontológica. Artes Médicas, Porto Alegre.

Stewart DW \& Shamdasani PN 1990. Focus groups: theory and practice applied social research methods series. Sage, Newbury.

Tamietti MB, Castilho LS \& Paixão HH 1998. Educação em saúde bucal para adolescentes: inadequação de uma metodologia tradicional. Arquivos em Odontologia 34(1):33-45.

Thomson WM, Locker D \& Poulton R 2000. Incidence of dental anxiety in young adults in relation to dental treatment experience. Community Dentistry Oral Epidemiology 28(4):289-294.

Watt RG 1997a. Stages of change for sugar and fat reduction in an adolescent sample. Community Dental Health 14(2):102-107.

Watt RG 1997b. Theoretical models - what do they tell us? In B Daly \& RG WATT (ed.). Designing and evaluating effective oral health promotion. Papers from the Oral Health Promotion Research Group. Conferência anual realizada na University of London.

Westphal MF, Bógus CM \& Faria MM 1997. Grupos focais: experiências precursoras do uso da técnica em programas educativos em saúde no Brasil. Comunicação proferida no 5o Congresso Paulista de Saúde Pública. Águas do Lindóia, São Paulo, 25-29 ago.

Artigo apresentado em 20/11/2002

Aprovado em 15/1/2003

Versão final apresentada em 10/3/2003 